\section{Category}

Synthesis of Natural Products and

Potential Drugs

\section{Key words}

\section{telaprevir}

stereoselective lithiation

\section{carboxylation}

classical resolution
G. J. TANOURY,* M. CHEN, Y. DONG, R. FORSLUND, V. JURKAUSKAS, A. D. JONES,

D. BELMONT (VERTEX PHARMACEUTICALS, BOSTON, USA)

Stereoselective Lithiation and Carboxylation of Boc-Protected Bicyclopyrrolidine: Synthesis of a Key Building Block for HCV Protease Inhibitor Telaprevir

Org. Process Res. Dev. 2014, 18, 1234-1244.

\title{
Synthesis of a Key Building Block for HCV Protease Inhibitor Telaprevir
}

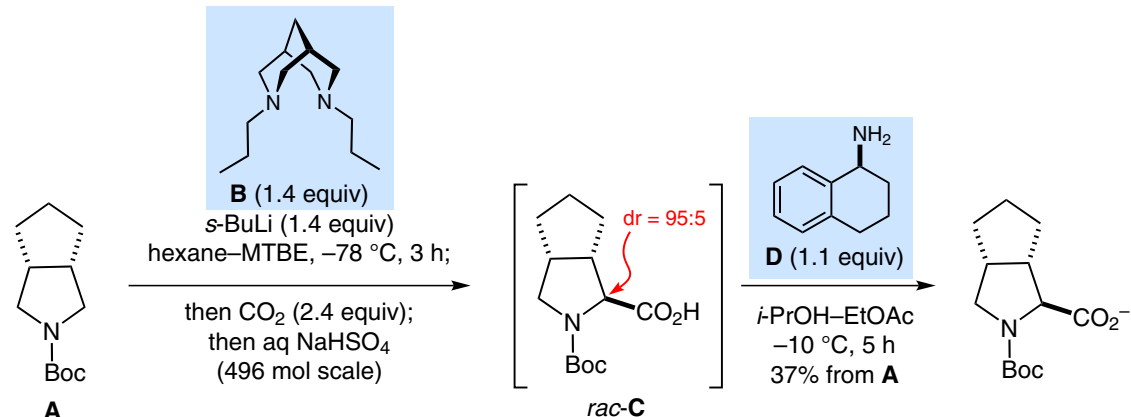<smiles>NC1CCCc2ccccc21</smiles>

A

rac-C<smiles>CC(C)(C)OC(=O)C1NCC2CCCC21</smiles>

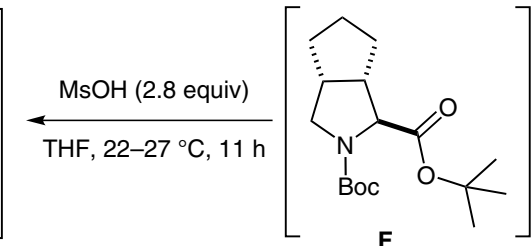

aq $\mathrm{NaHSO}_{4}$ (salt break) then $t$ - $\mathrm{BuOH}$ ( 7.6 equiv) $\mathrm{Boc}_{2} \mathrm{O}$ (1.4 equiv)

DMAP $(0.2$ equiv) MTBE, $22-27^{\circ} \mathrm{C}, 5 \mathrm{~h}$ (397 mol scale)<smiles>NC1CCCc2ccccc21</smiles>

$$
\begin{gathered}
\text { E } \\
\text { mp not reported } \\
\text { er }=99: 1 \\
d r=100: 0
\end{gathered}
$$$$
\text { then oxalic acid (1.2 equiv) }
$$$$
\text { i-PrOAc-MTBE, r.t., } 2.5 \mathrm{~h}
$$$$
68 \% \text { from } \mathbf{E}
$$<smiles>CC(C)(C)OC(=O)[C@H]1NC[C@@H]2CCC[C@H]12</smiles>

H<smiles>CN1CC2CC(C1)N1CCCCC2C1</smiles>

(-)-cytisine (I)

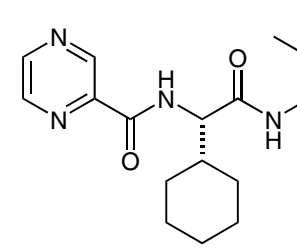

Telaprevir
Significance: The target molecule $\mathbf{H}$ is a fragment of the HCV protease inhibitor telaprevir. A largescale process for the synthesis of $\mathbf{H}$ entails a stereoselective lithiation-carboxylation of $\mathbf{A}$ to give rac-C followed by a resolution with $(S)$-1,2,3,4-tetrahydronaphthalen-1-amine (D). Two hundred kilograms of the target molecule $\mathbf{H}$ were manufactured in $27 \%$ overall yield by this route.

SYNFACTS Contributors: Philip Kocienski

Synfacts 2015, 11(1), 0004 Published online: 15.12.2014 Dol: 10.1055/s-0034-1379645; Reg-No.: K05914SF
Comment: An enantioselective synthesis of $\mathbf{C}$ via asymmetric lithiation-carboxylation using a variety of chiral diamine ligands was also investigated. For example the chiral diamine ligand (-)-cytisine developed by O'Brien and co-workers (J. Am. Chem. Soc. 2002, 124, 11870) provided ent-C in $44 \%$ yield and er $>$ 99:1 after crystallization. However, this route was not pursued owing to the high cost and uncertain supply of (-)-cytisine. 